\title{
Comparative Effect of Two Problem-solving Instructional Strategies on Students' Achievement in Stoichiometry
}

\author{
Shadreck Mandina ${ }^{1 *}$, Chukunoye Ochonogor ${ }^{2}$ \\ ${ }^{1}$ Department of Applied Education, Midlands State University, ZIMBABWE \\ ${ }^{2}$ Cape Peninsula University of Technology, Cape Town, SOUTH AFRICA \\ Received 5 Decebmer 2017 - Revised 13 July 2018 - Accepted 14 August 2018
}

\begin{abstract}
The study investigated the comparative effects of Selvaratnam, \& Fraser (1982) and Ashmore et al. (1979) problem-solving instructional strategies on Advanced Level students' achievement in Stoichiometry. The quasi-experimental design with a nonequivalent comparison group consisting of pre-and post-test measures was utilized in the study. The participants were 525 Advanced level chemistry learners drawn from 8 high schools from Gweru district. Data were collected using standardized achievement Tests in stoichiometry. The problem-solving instruction was implemented in four experimental schools while the remaining four control schools were taught using the conventional lecture method. Analysis of Covariance (ANCOVA) was used to analyze data. The findings indicated a statistical significant difference in the performance of students taught using the two problem-solving strategies and those taught using the conventional method. The Scheffe's post- hoc test indicated that students taught using the Ashmore et al. (1979) problem-solving instructional strategy performed significantly better than those taught with the Selvaratnam \& Fraser problem-solving strategy. Furthermore, it was also found that the performance of students in the experimental group was not influenced by gender. Chemistry teachers are therefore strongly recommended to use problem-solving instructional strategies in their classes to improve the abilities of learners in solving stoichiometry problems.
\end{abstract}

Keywords: achievement, chemistry education, gender, problem solving instruction, stoichiometry

\section{INTRODUCTION}

One of the major goals in science education is the development of problem solving skills which are critical in a highly technical, scientific, as well as complex modern society (Gongden, 2016). The development of such problem solving skills will enable learners to deal with various emerging challenges effectively. Therefore, development of students' problem solving skills is one of the needs of the hour. Recognising this instrumental role that science plays, it becomes important that science educators develop strategies of improving and promoting the teaching and learning of science (Argaw, Haile, Ayalew, \& Kuma, 2017). Chemistry is one of the science subjects that plays an important role in national development. As noted by Okafor (2000), the scientific development of any nation hinges upon the quality of chemical education offered in schools. Chemistry as a school subject is relevant to a number of manufacturing industries such as pharmaceuticals, food processing, agricultural, clothing and textiles, petrochemical as well as metallurgical industries (Gongden, 2016).

However, due to its abstract, complex and conceptually demanding nature, chemistry has been found to be difficult for most secondary school students (Adesoji, Omilani, \& Dada, 2017; Agogo \& Onda, 2014; Childs \& Sheehan, 2009; Kamisah \& Nur, 2013). As noted by Biglin (2005) these difficulties stem from the learner's lack of sufficient prior knowledge or cognitive development, learner's psychological development, mathematical anxiety, visual abilities, or instructional method employed. Studies by Gilbert and Treagust, (2009) further highlight that

(C) 2018 by the authors; licensee Modestum Ltd., UK. This article is an open access article distributed under the terms and conditions of the Creative Commons Attribution License (http://creativecommons.org/licenses/by/4.0/).

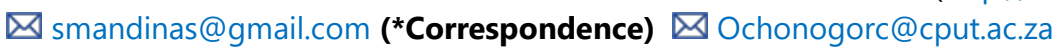




\section{Contribution of this paper to the literature}

- The study evaluates the comparative effect of two problem solving instructional strategies on students' achievement in stoichiometry.

- This study highlights that the use of problem-solving instructional strategies has shown a significant positive effect on enhancing students' achievement in stoichiometry.

misconceptions and problems with models and modelling often act as important impediments to students' learning in chemistry. From the researchers' observations and experience, learners become nervous when learning chemistry aspects that involve solving quantitative problems. In addition, the learners are always agitated when they are required to apply problem solving techniques to find solutions to quantitative problems in chemistry.

According to Naah and Sanger (2012), chemistry students find a number of concepts difficult to learn. Stoichiometry has been identified as one of the topics in chemistry that students find difficult to learn (Tan et al., 2010; Yildirım et al., 2011). Research has shown that the poor performance by Zimbabwean students in chemistry is as a result of their poor problem-solving in stoichiometry (Kazembe \& Musarandega, 2012). The Zimbabwe Schools Examinations Council (ZIMSEC, 2013) chemistry examiners report notes the difficulties that chemistry students have in performing numerical calculations involving the mole concept as well as writing of balanced equations.

Chemical stoichiometry has been found to be multi-topic, complex and abstract in nature as a result students find it difficult to comprehend (Sedumedi, 2014). Molnar and Molnar-Hamvas (2011) further note that stoichiometry is fundamental to all aspects of chemistry and requires students' deep problem solving skills. Problem solving skills are generic skills that contribute to success in solving problems including the ability to understand the problem as well as rules that can be applied to solve a problem. As noted by Seyhan (2015), problem solving skills include the ability to reason analytically, think critically and create productively. Ding \& Xu (2011) further note that, problem-solving skills include higher order cognitive processes and involve a series of abilities, such as visualization, association, abstraction, comprehension, manipulation, reasoning, analysis, synthesis, generalization, each needing to be managed and coordinated. The classroom learning experiences therefore need to be designed to scaffold and develop students' problem solving skills.

To be able to solve stoichiometric problems, students should not only possess good mastery of stoichiometry concepts, but also ability to construct and balance reaction equations and using them in calculation of the quantity of chemical substances (Molnar \& Hamvas, 2011). Furthermore, in stoichiometry, students are actively engaged in solving problems that are sophisticated (Sedumedi, 2014). To be actively engaged in solving sophisticated problems, students need to have knowledge structures that are well organised (Bledsoe \& Flick, 2012) which in most instances is lacking among high school students consequently they find stoichiometric problem-solving difficult to undertake. This lack of well-organized knowledge structures requires that chemistry educators intervene with different teaching and learning strategies to address students' problem-solving challenges and improve their capabilities in problem-solving.

Efforts to develop instructional strategies to enhance student's problem-solving abilities in chemistry have led to the development of many problem-solving models and has seen the establishment of these models in teaching and learning basic science (Adigwe, 1998; Nbina \& Joseph, 2011).This has resulted in the enhancement of the academic achievement of students. In the Zimbabwean context, as far as the researchers' knowledge is concerned no research has attempted to study how problem-solving instructional strategies can enhance the abilities of chemistry learners in problem-solving. This study, therefore, seeks to investigate how selected problem-solving models (Ashmore, Casey, \& Frazer, 1979; Selvaratnam \& Frazer, 1982) can facilitate the abilities of Zimbabwean Advanced Level chemistry students' in solving stoichiometry problems.

The frame work of Ashmore, Casey, and Frazer (1979) for solving problems in chemistry consists of the following stages: defining the problem goal, selecting information from problem statement, selecting information from memory and evaluation of the solution to the problem. The model is based on the premise that if students are to be successful in solving chemical problems then they must possess strong knowledge in chemistry, knowledge of problem solving strategies and tactics as well as confidence (Adesoji \& Babatunde, 2008).

On the other hand, model devised by Selvaratnam and Frazer, (1982). model has five steps which are: clarifying and defining the problem, selecting the key equation or relationship, deriving the relationship for the solution of the problem or calculation, collecting data, checking the units and calculating or solving the problem and finally reviewing, checking through steps 1-4, confirming the units and learning from the situation. As noted by Udo (2011) the learner is expected to perform a number of of sub-tasks such as reading through the problem statement, identifying the known and the unknown, sorting out and arrange the data in convenient manner; and focus on the problem that is to be solved. 


\section{Statement of the Problem}

Students' poor problem solving ability, learning difficulties and misconceptions in stoichiometry is an indication of the likelihood of a deficiency in instructional strategies used in the chemistry classroom a conclusion drawn by Gongden (2016). The Zimbabwe Schools Examinations Council (ZIMSEC) chief examiners reports over the years (2012-2017) report the lack of understanding of stoichiometric concepts and ability solve stoichiometric problems among learners. Currently, the instructional strategies being used in chemistry teaching have not realised considerable improvements in the quality of students' achievement in the subject to a considerable extent. As a result, developing better strategies of teaching chemistry has been and is becoming one of the core issues that scholars deal with in chemistry education. The focus on improving learners' problem-solving skills using problemsolving instructional strategies to foster a deeper and more meaningful understanding of stoichiometry therefore becomes important for chemistry educators.

\section{Objectives of the Study}

The study addressed the following objectives:

i) To determine the effect of the Ashmore, Casey \& Frazer (1979) problem-solving model and the Selvaratnam and Frazer, (1982) problem-solving model on the achievement of students in stoichiometry.

ii) To determine if gender has an influence on the achievement of students in stoichiometry when exposed to the Ashmore, Casey, and Frazer (1979) as well as Selvaratnam and Frazer, (1982) problem -solving models.

\section{Hypotheses of the Study}

$\mathbf{H O}_{1}$ : There is no significant difference in the performance of students taught using the two problem-solving instructional strategies and those taught using lecture method.

$\mathbf{H O}_{2}$ : There is no significant difference between the performance of female and male students taught stoichiometry using the two problem-solving instructional strategies and those taught using lecture method.

\section{RESEARCH METHODOLOGY}

The study employed a quasi-experimental research approach with a non-randomized, non-equivalent pre-test and post-test comparison group. This design was chosen since it is not possible to conduct true experiment on human beings. Furthermore as noted by Fatade, Mogari, and Arigbabu (2013) this design is associated with cause and effect relationships and is easier to set up than true experiments. The adoption of the quasi-experimental design in this study enabled the researchers to use intact classes during the implementation of the interventions thus ensuring that the smooth running of the school programmes was not disrupted. The use of intact classes made it possible for the researcher, to administer a treatment or intervention to some of the classes while the other classes act as the comparison group (McMillan \& Schumacher, 2010). The views of Arzi and White, (2005) seem to suggest that random selection is not possible in educational research, while Cook (2002) observes that researches involving the effectiveness of teaching strategies to improve student achievement random assignment are rare. Since it was not possible for the researcher to conduct a true experiment, non-equivalent comparison group design was used in the study (Johnson \& Christenson, 2012).

\section{Participants of the Study}

The sample consisted of 525 Advanced Level chemistry learners. The participants were drawn from eight randomly selected co-educational high schools in the district. The district has 13 high schools. The randomly selected schools were deemed to be equivalent (laboratory, facilities, and manpower), socioeconomic background and school type (public school). Argaw et al. (2017) identifies the non-equivalent control group design as the most commonly employed quasi-experimental design in educational research. This design however has limitations which can be overcome through the process of matching the experimental and comparison groups prior to the start of the intervention so as to make the two groups more comparable. Before the commencement of the experiment, the researchers had to administer a pretest to all high schools in the district. Based on the result, eight high schools that were found to have scored and obtained nearly the same mean score were selected. The researchers then divided the schools into two groups based on their geographical location and randomly assigned the two groups into experimental and comparison group. Four schools on the northern and eastern parts of the district constituted the comparison group (with 275 learners) while the experimental group was composed of the remaining four schools (with 250 learners) on the southern and western parts of the district. A distance of about $25 \mathrm{~km}$ separated the control and experimental schools. The learners in the comparison group (schools) were taught by their teachers 
Table 1. Summary of mean and standard deviation scores of the students in pre-test and post-test classified by treatment groups

\begin{tabular}{lccccc}
\hline Group & \multicolumn{2}{c}{ pre-test } & \multicolumn{2}{c}{ post test } & \\
\hline & $\mathbf{M}$ & SD & M & SD & Mean gain \\
\hline Experimental group 1. $\mathrm{n}=117$ & 40.0514 & 1.25987 & 56.7179 & 1.15852 & 16.6665 \\
\hline Experimental group 2 $\mathrm{n}=118$ & 40.9867 & 1.01156 & 56.6949 & 0.99149 & 15.7082 \\
\hline Comparison group $(\mathrm{n}=275)$ & 39.4425 & 1.26113 & 40.6160 & 1.15667 & 1.1735 \\
\hline
\end{tabular}

using the conventional lecture method. The learners in the experimental group (schools) were also taught by their teachers who served as research assistants after having been trained on the use of problem-solving instructional strategies. These research assistants implemented problem-solving instruction in their classes. Experimental group 1 was taught using the Ashmore, Cassey, and Fraser (1979) problem solving model while Experimental group 2 was taught using the Selvaratnam and Fraser (1982) problem solving model.

\section{Instruments for Data Collection}

Data for this study were collected using problem-solving achievement tests in stoichiometry. The test comprised of 25 multiple choice items. The test was validated by experts in chemistry education before its use in the pilot as well as in the actual study. The internal consistency of the test was evaluated using Cronbach alpha coefficient and found to be 0.84 which is an acceptable level of reliability.

\section{Method of Data Analysis}

The analysis of data was carried out using both descriptive statistics (mean, standard deviation) and inferential statistics (analysis of covariance, ANCOVA) using Statistical Package for Social Sciences (SPSS) version 20.0. The post-test score for stoichiometric problem-solving test was subjected to Analysis of Covariance (ANCOVA) using pre-test scores as covariates. The use of ANCOVA analysis was to "statistically control" for influence of confounding variables. A p-value of less than 0.05 was considered to be statistically significant.

\section{FINDINGS}

In this section the two research objectives raised were answered based on the results in Tables $\mathbf{1}$ and 2.

Research Objective 1: The effect of Ashmore, Casey E Frazer (1979) and Selvaratnam \& Frazer, (1982) problem-solving models on the achievement of students in stoichiometry.

Table 1 shows mean and standard deviation for the response of stoichiometry problem solving test. The result of the study shows the pre-test mean score of the experimental groups and that of the comparison group was nearly the same. As highlighted by Argaw et al. (2017) this enabled the researchers to infer the effect of the treatment (problem-solving instruction) after the intervention. Higher scores on the post-test form the experimental group than the comparison group can then be attributed to the treatment, on the basis that confounding variables would have been controlled.

From the data presented in Table 1, it was observed that the students in the two experimental groups (Ashmore et al. (1979) and Selvaratnam and Frazer (1982)) had mean scores of 56.6949 and 56.7179 and corresponding Standard deviations of 0.99149 and 1.15852 respectively. The mean score for the students in the control group was found to be 40.6160 and the standard deviation being 1.15667 . The observation implied that the use of the two models indicated a positive effect on the students' achievement in stoichiometry. The post test result shows that the two experimental groups had greatly improved than the comparison group and had much better mean gain scores.

The study went on further to statistically test the main effect of Selvaratnam and Frazer (1982) and Ashmore et al. (1979) problem-solving instruction on participants' overall achievement in stoichiometry. In this study, the use of ANCOVA enabled the researcher to isolate the effect of Selvaratnam and Frazer (1982) and Ashmore et al. (1979) problem solving instructional strategies after having statistically removed the effect of the covariate (pre-test scores).

The following null hypotheses (Ho) was tested at 0.05 levels of significance.

Null hypothesis: Ho: There is no significant difference in the mean achievement scores of students' taught using the Selvaratnam \& Frazer (1982) and Ashmore et al. (1979) problem-solving models and those taught with the conventional method.

Alternate hypothesis: $\mathbf{H}_{\mathbf{1}}$ : There is a significant difference in the mean achievement scores of students' taught using the Selvaratnam \& Frazer (1982) and Ashmore et al. (1979) problem-solving models and those taught with the conventional method. 
Table 2. The test of Between-Subjects Effects; Stoichiometry post-test

\begin{tabular}{lccccc}
\hline Source & Type III Sum of Squares & df & Mean Square & F & Sig. \\
\hline Pretest & 4.312 & 1 & 4.312 & 3.459 & .084 \\
\hline Group & 31140.261 & 2 & 15570131 & 12491.765 & .000 \\
\hline
\end{tabular}

Table 3. Scheffe's post hoc analysis of post-test scores for treatment groups

\begin{tabular}{llccc}
\hline Treatment (I) & Treatment $(\mathbf{J})$ & Mean difference $(\mathbf{I}-\mathbf{J})$ & Std. error & Sig \\
\hline \multirow{2}{*}{ Comparison } & Experimental group 1 & -15.3706 & 1.6144 & .000 \\
\cline { 2 - 5 } & Experimental group 2 & -10.5207 & 1.6215 & .000 \\
\hline \multirow{2}{*}{ Experimental group 1 } & Comparison & 15.3706 & 1.5978 & .000 \\
\cline { 2 - 5 } & Experimental group 2 & 4.8499 & 1.6215 & .000 \\
\hline \multirow{2}{*}{ Experimental group 2 } & Comparison & 10.5207 & 1.5978 & .000 \\
\cline { 2 - 6 } & Experimental group 1 & -4.8499 & 1.6144 & .000 \\
\hline
\end{tabular}

Table 4. Comparison of male and female students across groups in the Stoichiometry Achievement Test

\begin{tabular}{lllcc}
\hline Group & Gender & Mean & Standard deviation & $\mathbf{N}$ \\
\multirow{2}{*}{ Comparison group } & Female & 40.9912 & 1.25519 & 113 \\
\cline { 2 - 5 } & Male & 40.8613 & 1.13230 & 137 \\
\hline \multirow{2}{*}{ Experimental group 2 } & Female & 51.2542 & 2.16232 & 59 \\
\cline { 2 - 5 } & Male & 51.6271 & 1.63895 & 59 \\
\hline \multirow{2}{*}{ Experimental group 1 } & Female & 56.0690 & 3.28667 & 58 \\
\cline { 2 - 5 } & Male & 56.5085 & 1.26454 & 59 \\
\hline
\end{tabular}

The results of the hypothesis test are presented in Table 2.

The result in Table 2 suggest that the treatment (Selvaratnam and Frazer (1982) and Ashmore et al. (1979) problem-solving models is a significant factor on students' achievement in stoichiometry. Thus the hypothesis $\mathrm{H}_{0}$ that there is no significant difference is rejected. The implication is that a significant difference exists in the mean scores of subjects exposed to the two problem-solving models and those not exposed.

\section{Scheffe's Post hoc Analysis}

To determine which of the two methods was most effective in teaching stoichiometry, a post-hoc analysis was conducted using Scheffe's Post Hoc test. The advantage of using this procedure is that it is conservative and covers a broad range of complex tests including post-hoc relationships among many groups (Kim, 2015). Scheffe's test has the advantage of giving the experimenter the flexibility to test any comparisons that appear interesting. The results are summarized in Table 3.

The results in Table 3 show that learners in the two experimental groups are significantly different from those in the control group and that their performance was better than those in the control group. Moreover, the Scheffe's post-hoc test also indicated that there was a significant differences between the two experimental groups (those taught using the Ashmore et al problem solving model did significantly better than those taught using the Selvaratnam-Frazer problem-solving model.

Research Objective 2: The influence of gender on the mean achievement scores of students taught Stoichiometry using problem-solving instruction.

Table 4 shows that the males in the two respective experimental groups had higher mean scores than their female counterparts.

The following hypothesis was tested at the 0.05 levels of significance.

Ho1: $_{\text {1 }}$ There is no significant difference in the performance of male and female chemistry students exposed to Selvaratnam \& Frazer and Ashmore et al problem-solving models.

$\mathbf{H}_{\mathbf{1}}$ : There is a significant difference in the performance of male and female chemistry students taught using Selvaratnam-Frazer and Ashmore et al problem-solving models.

The data in Table 5 indicates that the F-ratio for the gender factor was not significant since 0.05 is less than 0.171 $(\mathrm{P}>0.05)$. The conclusion is that there was no significant difference between the mean achievement scores of male and female students taught stoichiometry using the models. 
Table 5. ANCOVA summary Table for post-test Performance Scores based on gender

\begin{tabular}{lcccccc}
\hline Source & Sum of Squares & df & Mean Square & $\mathbf{F}$ & Sig. & Partial Eta Squared \\
\hline Corrected Model & $21692.770^{\mathrm{a}}$ & 6 & 3615.462 & 1181.139 & .000 & .937 \\
\hline Intercept & 5643.119 & 1 & 5643.119 & 1843.557 & .000 & .794 \\
\hline pretest & 31.654 & 1 & 31.654 & 10.341 & .001 & .021 \\
\hline gender & 5.743 & 1 & 5.743 & 1.876 & .171 & .004 \\
\hline group & 21335.570 & 2 & 10667.785 & 3485.071 & .000 & .936 \\
\hline gender * group & 7.922 & 2 & 3.961 & 1.294 & .275 & .005 \\
\hline Error & 1463.155 & 478 & 3.061 & & & \\
\hline Total & 1103092.000 & 485 & & & & \\
\hline Corrected Total & 23155.926 & 484 & & & &
\end{tabular}

\section{DISCUSSION}

The research findings reveal that problem-solving instruction is more effective on improving problem-solving skills of chemistry learners in stoichiometry than the conventional teaching method. The finding of this study is in consonance with the view of Çaliskan, Sezgin Selçuk, and Erol (2010), Noh, Jeon, and Huffman (2005) who assert that problem-solving instruction enhances achievement in Chemistry more than conventional lecture method of teaching. Independent interpretations from both descriptive statistics and analysis of covariance (ANCOVA) showed clearly that the problem-solving instruction enhance student achievement in chemistry better than the conventional method. This result is in agreement with the results of earlier studies carried out by Aka, Guven, and Aydogdu (2010) as well as Akınoğlu and Tandoğan (2007) both of which established the relative efficacy of problem-solving instructional strategies in fostering students' achievement in school subjects relative to the expository method. The findings are in accord with Hung (2008) who noted that the use of problem-solving instruction significantly increased students' achievement in computer programming.

With reference to the second research question (To what extent would gender influence the mean achievement scores of students taught with problem-solving instructional strategies?), the effect of problem-solving instruction on stoichiometry problem-solving abilities and achievement of female and male students in the treatment group was not found to be statistically significantly different. Literature has reported many findings (Donnelly et al., 2012; Madsen et al., 2013; Richardson \& O'Shea, 2013) revealing the exceptional performance of male students than their female counterparts in science. However, in the present study problem-solving instruction reduced the gender gap in stoichiometry problem-solving skills and performance indicating that gender is not a perfect predictor as far as achievement in stoichiometry concerned, whether students are taught using problem- solving approach or the conventional method. This finding was also in consonant with Adesoji and Jimoh's (2007), as well as Gok (2014) that gender has no effect on students' performance in chemistry and physics respectively, a position also held by Adesoji and Babatunde (2008) who also found out that gender difference had no influence on students' performance in chemistry and science examinations.

The findings of men out performing women may perhaps have been perpetuated by gender stereotyping which is commonly based on cultural beliefs. This finding implies that whether a student is male or female, gender does not make a difference in their academic achievement therefore students' academic achievement is not a function of gender. All students irrespective of their sexes benefited in about the same margin from the use of problem-solving instructional strategies.

\section{CONCLUSIONS}

It can therefore concluded that the application problem-solving strategies is more effective in helping students improve their problem solving performance than conventional lecture method. This clearly supports the implementation of problem-solving instruction in the chemistry classroom. The implication is that students who were taught using problem-solving strategies had well mastered the strategies of solving stoichiometry and ionic equilibrium problems better than those taught using the conventional method.

The gender difference among students exposed to problem-solving instruction was not significant implying that problem-solving instruction is capable of facilitating learning in similar manner among male and female students in stoichiometry and ionic equilibria. 


\section{RECOMMENDATIONS}

Based on the major findings of this study, the following recommendations are made:

It is evident from the study that, problem-solving instructional teaching methods are effective in improving students' achievement in stoichiometry and ionic equilibria. Therefore, chemistry teachers are strongly recommended to use these teaching methods in their lessons to facilitate students' problem solving performance.

Considering that the goal of chemistry education is to improve problem solving skills of learners, findings from the study suggest need for proper training of pre service teachers in problem solving instruction as well as how to implement effectively problem-solving instruction. Furthermore in-service training through symposiums and workshops should be organized and made compulsory for practicing chemistry teachers so that they can embrace the skills of the problem-solving strategies for effective implementation of the strategies in teaching chemistry.

The teacher education should be geared towards preparation of Chemistry teacher to acquire and maintain appropriate problem solving strategies which strongly enhance achievement of Chemistry students at high school level.

\section{SUGGESTIONS FOR FUTURE RESEARCH}

Future researchers may conduct longitudinal studies on the effect of problem-solving instructional strategies on student achievement in the chemistry classroom.

Furthermore, future studies may consider replicating the study in other chemistry topics.

\section{REFERENCES}

Adesoji, F. A., \& Babatunde, A. G. (2008). Investigating Gender Difficulties and Misconceptions in Inorganic Chemistry at the Senior Secondary Level. International Journal of African and African American Studies, 2(1), 17.

Adesoji, F. A., Omilani, N. A., \& Dada, S. O. (2017). A Comparison of Perceived and Actual; Students' Learning Difficulties in Physical Chemistry. International Journal of Brain and Cognitive Sciences, 6(1), 1-8. https:/ / doi.org/10.5923/j.ijbcs.20170601.01

Adigwe, J. C. (1998). Three problem-solving instructional strategies and their effect on Nigerian student's attainment in chemistry. Research in Education, 60, 54 - 67. https:/ / doi.org/10.1177/003452379806000106

Agogo, P. O., \& Onda, M. O. (2014). Identification of Students Perceived Difficult Concepts in Senior Secondary School Chemistry in Oju Local Government Area of Benue State, Nigeria. Global Educational Research Journal, 2(4), 44-49.

Aka, E. G., Guven, E., \& Aydogdu, M. (2010). Effect of Problem Solving Method on Science Process Skills and Academic Achievement. Journal of Turkish Science Education, 7(4), 13-25

Akınoğlu, O., \& Tandoğan, R.O. (2007). The Effects of Problem-Based Active Learning in Science Education on Students' Academic Achievement, Attitude and Concept Learning. Eurasia Journal of Mathematics, Science $\mathcal{E}$ Technology Education, 3(1), 71-81. https:// doi.org/10.12973/ ejmste/75375

Argaw, A. S., Haile, B. B., Ayalew, B. T., \& Kuma, S. G. (2017). The Effect of Problem Based Learning (PBL) Instruction on Students' Motivation and Problem Solving Skills of Physics. EURASIA Journal of Mathematics, Science and Technology Education, 13(3), 857-871. https:/ / doi.org/10.12973/eurasia.2017.00647a

Arzi, H. J., \& White, R. T. (2005). Longitudinal studies: Designs, validity, practicality, and value. Research in Science Education, 35(1), 137-149. https:/ / doi.org/10.1007/s11165-004-3437-y

Ashmore, A. D., Frazer, M. J., \& Casey, R. J. (1979). Problem solving and problem solving network in Chemistry. Chemistry Education, 56(6), 377-379. https:/ / doi.org/10.1021/ed056p377

Bledsoe, K. E., \& Flick, L. (2012). Concept development and meaningful learning among electrical engineering students engaged in a problem-based laboratory experience. Journal of Science Education and Technology. 21(2), 226-245. https:/ / doi.org/10.1007/s10956-011-9303-6

Çaliskan, S., Sezgin Selçuk, G., \& Erol, M. (2010). Instruction of problem-solving strategies: Effects on physics achievement and self-efficacy beliefs. Journal of Baltic Science Education, 9(1), 20-34.

Childs P. E., \& Sheehan M. (2009). What's difficult about Chemistry? An Irish perspective, Chemistry Education Research and Practice, 10, 204-218. https://doi.org/10.1039/B914499B

Ding, N., \& Xu, Y. (2011) Improving Female Students' Physics Learning in High School. In: M. M. H. Cheng, W. W. M. So (Eds) Science Education in International Contexts. Sense Publishers, Netherlands. https:/ / doi.org/10.1007/978-94-6091-427-0_9 
Donnelly, R., MacPhee, C., \& Bates, S. (2012). The performance gender gap in undergraduate physics. Proceedings of the HEA STEM Learning and Teaching Conference. London, England. https:/ / doi.org/10.11120/stem.hea.2012.069

Fatade, A. O., Mogari, D., \& Arigbabu, A. A. (2013). Effect of Problem-Based Learning on Senior Secondary School Students' Achievements in Further Mathematics. Acta Didactica Naponcensia, 6(3), 27 - 44.

Gok, T. (2014). Peer Instruction in the Physics Classroom: Effects on Gender Difference Performance, Conceptual Learning, and Problem Solving. Journal of Baltic Science Education, 13(6), 776-788.

Gongden, E. J. (2016). The Effects of Analogy on Male and Female Chemistry Students'. Problem-Solving Ability in Electrolysis. International Journal of Scientific Research in Education, 9(1), 1-6.

Hung, Y.-C. (2008). The Effect of Problem-Solving Instruction on Computer Engineering Majors' Performance in Verilog Programming. IEEE Transactions on Education, 51(1), 131-137. https:// doi.org/10.1109/TE.2007.906912

Johnson, B., \& Christenson, L. (2012). Quantitative, qualitative, and mixed approaches. (4th edn.). University of South Alabama: SAGE Publications, Inc.

Kamisah, O., \& Nur, S. (2013). Conceptual understanding in secondary school chemistry: A discussion of the difficulties Experienced by students. American Journal of Applied Sciences, 10(5), 433-441. https://doi.org/10.3844/ajassp.2013.433.441

Kazembe, T. C., \& Musarandega, A. (2012). Student Performance in A-level Chemistry Examinations in Makoni District, Zimbabwe. Eurasian Journal of Physics and Chemistry Education, 4(1), 2-29. https://doi.org/10.12973/ejpce.2009.00048a

Kim, H. Y. (2015). Statistical notes for clinical researchers: post-hoc multiple comparisons. Restorative Dentistry $\mathcal{E}$ Endodontics, 40(2), 172-176. https:/ / doi.org/10.5395/rde.2015.40.2.172

Madsen, A., McKagan, S. B., \& Sayre, E. C. (2013). Gender gap on concept inventories in physics: What is consistent, what is inconsistent, and what factors influence the gap? Physical Review Special Topics-Physics Education Research, 9(020121), 1-15. https:/ / doi.org/10.1103/PhysRevSTPER.9.020121

McMillan, J., \& Schumacher, S. (2010). Research in Education. Evidence base Inquiry (7th Ed.), International Edition Boston: Pearson Education Inc.

Molnar, J., \& Molnar-Hamvas, L. (2011). LEGO-Method-New Strategy for Chemistry Calculation. US-China Education Review, B 7, 891-908.

Naah, B. M., \& Sanger, M. J. (2012). Student misconceptions in writing balanced equations for dissolving ionic compounds in water. Chemistry Education Research Practice, 13, 186-194. https://doi.org/10.1039/C2RP00015F

Nbina, J. B., \& Joseph, O. B. (2011). Assessment of the Effects of Problem-solving Instructional Strategies on Students' Achievement and Retention in Chemistry with Respect to Location in Rivers State. World Journal of Education, 1(2), 74 - 79. https:/ / doi.org/10.5430/wje.v1n2p74

Noh, T., Jeon, K., \& Huffman, D. (2005). The Effects of Thinking Aloud Pair Problem Solving on High School Students' Chemistry Problem-Solving Performance and Verbal Interactions. Journal of Chemical Education, 82(10), 1558-1564. https:/ / doi.org/10.1021/ed082p1558

Okafor, N. P. (2000). Laboratory resources and utilization as correlates of chemistry students' learning outcomes. Proceedings of the 41st Conference of the Science Teachers' Association of Nigeria, 169-173.

Richardson, C. T., \& O'Shea, B. W. (2013). Assessing gender differences in response system questions for an introductory physics course. American Journal of Physics, 81(3), 231-236. https:/ / doi.org/10.1119/1.4773562

Sedumedi, T. D. T. (2014). The Use of Productive Inquiry in the Teaching of Problem Solving in Chemical Stoichiometry. Mediterranean Journal of Social Sciences. 5(20), 1346-1359. https:/ / doi.org/10.5901/mjss.2014.v5n20p1346

Selvaratnam, M., \& Frazer, M. J. (1982). Problem Solving in Chemistry. London: Heinemann Educational Publishers.

Seyhan, G. H. (2015). The effects of problem solving applications on the development of science process skills, logical thinking skills and perception on problem solving ability in the science laboratory. Asia-Pacific Forum on Science Learning and Teaching, 16(2), 1-31.

Tan, K. C. D., Treagust, D. F., Chandrasegaran, A. L., \& Mocerino, M. (2010). Kinetics of acid reactions: making sense of associated concepts. Chemistry Education Research and Practice, 11, 267-280. https://doi.org/10.1039/C0RP90008G 
Udo, M. E. (2011). Effects of Problem-Solving, Guided-Discovery and Expository Teaching Strategies on Students' Performance in Redox Reactions African Research Review: An International Multidisciplinary Journal, Ethiopia, 5(4) 231-241.

Yildırım, N., Kurt, S., \& Ayas, A. (2011). The Effect of the Worksheets on Students' Achievement in Chemical Equilibrium. Journal of Turkish Science Education, 8(3), 44-58. Retrieved from http:/ / hdl.handle.net/11693/21794

Zimbabwe Schools Examination Council (2012). Chief examiner's report. Harare: ZIMSEC

Zimbabwe Schools Examination Council (2013). Chief examiner's report. Harare: ZIMSEC.

Zimbabwe Schools Examination Council (2014). Chief examiner's report. Harare: ZIMSEC.

Zimbabwe Schools Examination Council (2015). Chief examiner's report. Harare: ZIMSEC.

Zimbabwe Schools Examination Council (2016). Chief examiner's report. Harare: ZIMSEC.

Zimbabwe Schools Examination Council (2017). Chief examiner's report. Harare: ZIMSEC.

\section{http://www.ejmste.com}

